\title{
Editorial material
}

\section{Editorial: The Future of The Leadership Quarterly}

\author{
John Antonakis \\ Faculty of Business and Economics \\ University of Lausanne \\ john.antonakis@unil.ch
}

in press

The Leadership Quarterly

\section{Acknowledgements:}

I would like to thank Leanne E. Atwater, José M. Cortina, David V. Day, Jeffrey R. Edwards, Saskia Faulk, William L. Gardner, S. Alexander Haslam, James LeBreton, Michael D. Mumford, Steven G. Rogelberg, Victoria Wetherell, and Francis J. Yammarino for helpful comments received on this editorial.

Particular thanks go to Victoria Wetherell, our publisher, who has also played a key part in helping me to transition in the role of editor. Vicki has been very reassuring, helped me in spearheading the new editorial strategy of the journal, and strongly supported the efforts we are taking to promote the journal on the web and on social media platforms. 
Leadership is a universal phenomenon and has been studied by scholars since antiquity. Leadership is a key piece for solving social sciences puzzles, whether applied to the functioning of individuals, groups, organizations, or societies. How institutions and collectives decide who takes the helm, and what determines whether the leader is effective-however defined-is worthy of serious scientific investigation. We have, in the research community, made inroads to understanding how leadership works: Its antecedents, consequences, and contextualized nature. And, judging from the interest afforded to leadership in practice and academia — whether in general or specialized journals - leadership as a topic has earned its rightful place at the table of social science phenomena. Still, there is much to learn and most of this consequential work will be published in The Leadership Quarterly.

My involvement with the journal began in summer 2001, when many of the world's top leadership researchers were gathered at Binghamton University to attend the festschrift for Bernard M. Bass — a founding editor of The Leadership Quarterly. There I first met Robert J. House too, another founding editor. I was a post-doc at the time and how delighted and excited I was to meet them — their work inspired my academic raison d'être. Bernie and Bob probably played the biggest role in rekindling interest in leadership at a time (i.e., 1970s and 1980s) when it was not taken very seriously by many social sciences scholars. They also imagined the unimaginable: To start a journal exclusively focused on leadership!

That festschrift and a symposium hosted by William L. Gardner at "Ole Miss" (i.e., the University of Mississippi) in summer 2002 - in cooperation with the then editor of The Leadership Quarterly, James G. "Jerry" Hunt—were catalysts for many things to come including collaborations and friendships that still thrive today. However, never did I imagine where life's currents would take me since then. I feel a similar delight and excitement today as the new editor in chief of The Leadership Quarterly. Following the paths charted by such towering scholars and 
others who came before me is humbling, but it is challenging as well. These challenges will motivate me to work diligently and enthusiastically to continue the journey of my predecessors. Our journal will maintain its role as a top scholarly outlet for leadership research with the goal of publishing the best scientific research on leadership: Research that makes a contribution, is rigorous, and informs basic research or practice.

I have learned much over the last six years as an associate editor under Leanne E.

Atwater. She is passing the journal to me in shipshape order. She was instrumental in putting our current editorial structure in place and moving the journal into the digital era. Leanne was at the helm during a pivotal time in our journal's history, one in which the journal's reputation was strengthened to the point where we now receive many hundreds of submissions per year and face an embarrassment of riches. We are fortunate to be very selective about what we accept. Our acceptance rate is just a bit below $10 \%$, yet we still publish a substantial number of high-quality articles. Leanne's leadership was also visible during a particularly difficult period too that was marked by several retractions. As I mentioned in a recent editorial board meeting, and borrowing from another great leader, Winston Churchill: "She did not want to be the lion but it fell on her to give the lion's roar!"

All previous editors have played a significant role in developing the reputation of our journal (see Atwater, Mumford, Tosi, \& Yammarino, 2014). My development as scholar and editor has benefitted much from my interactions with the previous editors including Francis Yammarino and Michael Mumford, who incarnate what a consummate editor should be. Like so many others, I am forever in debt to Jerry Hunt. He did much for the journal- - he also accepted my first two articles and boy how fun it was to be around such a chronicler, raconteur, but also cowboy! Two more instrumental individuals taught me much during my time as board member 
and then associate editor of Organizational Research Methods: Former editor José Cortina and current editor James LeBreton.

\section{What will mark my term?}

All previous editors of The Leadership Quarterly had a few firsts (Atwater, et al., 2014): What are the firsts that will mark my term? One noticeable element is that I am the first European editor in chief, a Swiss who is U.S. trained, having a South African accent and a Greek name (go figure!). Beyond this demographic nicety, what I think will define my term are three key points, informed by a survey that I commissioned in early 2016, wherein board members gave their opinions about the status of the journal, how it compares to competitor journals, and how it should evolve. I also had discussions with board members at the 2016 board meeting at the Academy of Management Conference following my presentation of the vision I had for the journal. I consulted too with former editors of the journal as well as with the publisher and several senior scholars and methodologists. I also recruited the new associate editors on the basis of this vision. The three key points include:

1. Expanded editorial team: I have significantly broadened the editorial team. In addition to a yearly review editor, the team is now composed of five senior associate editors and nine associate editors who decision manuscripts, and a junior associate editor that assists me with article screening, follow-up, general administration, and journal promotion. The bigger team was motivated by the increased volume of manuscripts we handle and ensures that the action editors maintain a reasonable workload and provide timely feedback to submitting authors. We now have a good mix of eminent and distinguished mid-career scholars, as well as early career rising stars. This expansion of breadth is also evident in the editorial board, where we have added more than 30 new board members including many well-known names. 
2. Broader disciplinary focus: The broadening of the editorial team and board explains the second major change: The journal is now in a better position to evaluate a wider range of manuscripts from different disciplines. Beyond the management, organizational behavior, and industrial-organizational psychology backgrounds one would expect from an editorial team of a leadership journal, we now have significant expertise in various branches of social psychology, evolutionary and biological psychology, strategy and organizational theory, research methods, as well as behavioral economics and political science. Leadership can and should be studied creatively from many perspectives; if we are to have a broader influence on science and become a "bigger tent" journal, we must publish articles from diverse disciplines and from a multidisciplinary point of view. This broadening of focus ensures that we reify the original mission of the journal, which is to be international and interdisciplinary.

3. Different article types: Beyond the disciplinary breadth, we will now publish several new types of articles. Briefly, given a variety of structural factors, conditions, and cultural practices, our science is threatened by five major impediments, which may as well be called diseases: (a) a rapacious appetite for statistically significant results ("significosis"), (b) an incessant desire for novelty ("neophilia"), (c) a zeal for new theory ("theorrhea"), (d) a paucity of rigor in theory generation and testing ("arigorium") and (e) a tendency to produce lots of trite, fragmented, and disjointed work ("disjunctivitis").

Consequently, beyond the usual articles, The Leadership Quarterly will now publish a broader range of articles. The general idea here is that articles that make a contribution can do so not only because they are novel, but also because they report important discoveries, or contribute to cumulative scientific work; the latter is currently heavily hindered by our collective failure to publish robustly done but non-significant research. We need to be more critical and creative about how we do research, and develop more precise models, test them in a more rigorous 
manner, and cull them if needed. In these ways, we will contribute to more cohesive and useful science.

\section{Types of articles that LQ will publish}

In order for our science to be critical, self-correcting, and transparent, we will be accepting a wide array of articles at The Leadership Quarterly. We must publish research that is well conducted; whether a novel or cumulative contribution, it must be rigorous and useful for advancing science or practice. These article types are:

1. Full length articles: These include articles that have typically been published in the journal as well as some new types; these changes have been made to broaden what can be published and also to encourage more critical reflection on what is being researched. These articles will include (a) empirical studies (deductive or inductive), (b) theoretical articles, (c) meta-analyses, (d) narrative reviews, (e) in-depth critiques and reflections that shed new light on leadership as a phenomenon, (f) applied methodological articles, that present more robust ways in which to study leadership (and ideally other topic areas), and (g) adversarial collaborations and debates that exchange views on a particular topic.

2. Short communications: To address the lack of replication and the resulting biased distribution of effects, we will henceforth consider (a) replication studies, whether providing additional evidence for or against a particular theory, and (b) methodologically strong studies that present null results. These studies must, of course, be robustly designed and well powered; their contribution will be judged in terms of the importance of the topic and whether the findings can be informative for meta-analysis, reviews, and critiques.

3. Commentaries of published articles: These concern critiques of articles published in the journal and should extend, reinterpret, or question findings presented in the journal. 
4. Proposals — registered reports or results-masked articles: These include two types

of articles, which share a common platform in that the front end of the paper is first reviewed (i.e., introduction, literature review, method), followed by a second stage wherein the findings are reviewed. The two types of articles include: (a) registered reports concerning proposals to undertake an original empirical study (i.e., the data have not been gathered yet) and (b) resultsmasked manuscripts concerning studies for which data already have been gathered, but which are not reported in the proposal. Authors of a registered report proposal that is accepted gather the data. Then, for both types of accepted proposals, findings are reported and reviewed. If conclusions follow faithfully from the proposal, the article will normally be accepted, regardless of the findings and their statistical significance. Of course, registered reports have advantages over results-masked manuscripts because unlike the latter, the former can be revised following feedback from the review process.

5. Yearly Review articles: A yearly review editor is fully responsible for this category of articles; we use a two-stage review process in that a proposal is first reviewed, which if approved is followed by the full manuscript. These articles are published once per year and concern reviews, integrations, meta-analyses and the like about leadership, broadly defined. In particular, we seek manuscripts that will launch a new line of research, redirect existing research streams, lay out research agendas, or shut down lines that have overstayed their welcome. We want our yearly review articles to "push the envelope!"

6. Special issue articles: Proposals for special issues should be sent to me directly for consideration. To ensure that the editorial policy of the journal is coherent, a member of the editorial team will normally be involved in some capacity in editorial decisions of special issues. 


\section{I submitted my manuscript: Now what?}

Given that I have been processing new submissions since August 2016, I would like to make a few points about how submissions will be handled. For substantive details of how to reduce the likelihood of getting desk rejected, refer to my position paper in this issue of the journal and in particular the section titled: "How to make a more useful contribution to the research record" (Antonakis, 2017). There, I discuss issues concerning better theorizing, not ignoring endogeneity, designing realistic experiments, conducting rigorous qualitative research, declaring conflicts of interest, being transparent with data, methods, and reporting, and being an honest broker.

With respect to the type of manuscript submitted, authors must carefully consider the importance of clearly articulating a compelling motivation for the study based on the type of manuscript submitted. Ideally, the "big hook" must be communicated quickly in the first few paragraphs of the introduction. "Gap-spotting" or "never been done before" introductions do not themselves provide a sufficient justification for a study. Of course, manuscripts should be written in crisp prose given that most readers do not appreciate being lost in a logorrheic labyrinth of lofty language (I trust I made my point!).

I first receive manuscripts for initial evaluation and decide if they go out for review. The desk rejection rate with the previous editor was around 50\%; however, I foresee it increasing under my editorship because, given the volume of manuscripts we are now dealing with, there is no other way to use our editorial and reviewer resources wisely and efficiently. Associate editors and reviewers should spend their time making substantive and constructive comments on manuscripts with potential. As far as this journal is concerned, we expect authors to submit their best leadership research to us - work that is comparable in quality to that sought by top journals in the broader domain of management research. Note that manuscripts with fixable and obvious 
problems (e.g., wrong estimator for testing mediation or panel data) may be sent back to authors for revision prior to being sent out for review.

If I decide that the manuscript can potentially make a solid contribution to the research record, I will assign it to an action editor-either a senior associate editor, an associate editor, or myself, according to our in-house editorial expertise (manuscripts of editorial team members will be handled by a former editor). I will also assign the reviewers. Typically, two reviewers will comment on the manuscript but I will assign three reviewers if the manuscript is complex or requires reviewers with different expertise. Action editors will use reviewer comments to make an informed decision on the manuscript. However, action editors will exercise editorial discretion and make the decision they believe is right as opposed to "voting counting."

Our goal as editors is to encourage revision of articles that have a chance to be published; thus, the editors will constructively work with the authors who have received a revision request. Of course, there are no guarantees that revised manuscripts will ultimately be published, but the intent is there. That is, manuscripts that receive a solid revision (i.e., not a high risk one) should have a relatively good chance to get to the finish line; to the extent possible we will try to avoid giving authors a rejection decision in latter rounds of the review process.

\section{Conclusion}

It is my hope that The Leadership Quarterly will play a leading role in improving scientific practice in our field by sending the right signals with respect to targets and incentives we give to authors. I trust too that our editorial strategy will set a good example for other journals, and contribute to fixing some of the problems that challenge science. After all, leadership is about being a first mover, setting the example, and honestly signaling one's values and intentions. 
I am very proud to have been entrusted to lead the journal for the next few years. Now it is time to get down to business; we have to show that at The Leadership Quarterly we practice what we publish. 


\section{References:}

Antonakis, J. (2017). On doing better science: From thrill of discovery to policy implications. The Leadership Quarterly.

Atwater, L. E., Mumford, M. D., Tosi, H. L., \& Yammarino, F. J. (2014). Editorial: 25 years of the Leadership Quarterly. The Leadership Quarterly, 25(1), 3-5. 